\title{
Stem cell factor restores hepatocyte proliferation in IL-6 knockout mice following $70 \%$ hepatectomy
}

\author{
Xiaodan Ren, ${ }^{1}$ Cory Hogaboam, ${ }^{2}$ Audra Carpenter, ${ }^{1}$ and Lisa Colletti ${ }^{1}$ \\ ${ }^{1}$ Department of Surgery and \\ ${ }^{2}$ Department of Pathology, University of Michigan Medical School, Ann Arbor, Michigan, USA
}

\begin{abstract}
Stem cell factor (SCF) is a molecule with known proliferative effects on hematopoietic cells. More recent studies suggest that this molecule may also have effects on cellular differentiation and proliferation in other types of cells. The current investigations demonstrate that there is a large reservoir of SCF in the liver, that hepatic SCF levels change dramatically following partial hepatectomy in mice, and that SCF blockade, either by administration of anti-SCF antibodies or by using genetically altered, SCF-deficient mice, inhibits hepatocyte proliferation after partial hepatectomy; if SCF is replaced in the genetically SCF-deficient mice after partial hepatectomy, hepatocyte proliferation is restored to that seen in WT animals. Furthermore, SCF administration to IL-6 knockout mice also restores hepatocyte proliferation to normal. In vitro studies using primary mouse hepatocytes demonstrate that SCF causes hepatocyte proliferation and is induced by IL- 6 and that treatment with anti-SCF antibodies inhibits IL-6-induced hepatocyte proliferation. Further in vivo studies in IL-6 knockout mice demonstrate that SCF administration to these animals increases p-stat 3 levels, suggesting that the SCF-induced increase in hepatocyte proliferation in this system is stat3-mediated.

J. Clin. Invest. 112:1407-1418 (2003). doi:10.1172/JCI200317391.
\end{abstract}

\section{Introduction}

Patients regularly undergo partial hepatectomy to treat benign and malignant hepatic tumors. In most cases, the remnant liver undergoes hyperplasia until the normal hepatic mass is reestablished (1). As long as an adequate healthy liver remnant (approximately $30-35 \%$ of the patient's initial hepatic mass) remains after the surgical procedure, the patient usually recovers without incident (1). Despite the fact that only $30-35 \%$ of the normal hepatic parenchyma is necessary to sustain a patient, following resection the remaining liver tissue proliferates until the previous hepatic mass is restored (1). This is a tightly controlled process: once the original liver mass is restored, the process ceases and additional hyperplasia does not occur (1). While this phenomenon has been well described in many species and for many years, the specific mechanisms and factors involved remained to be completely defined (1).

Many cytokines are upregulated during acute liver injury, including TNF- $\alpha$, IL-1, IL-6, hepatocyte growth factor, TGF- $\alpha$, macrophage inflammatory protein-2 (MIP-2), stem cell factor (SCF), and many others (2-8).

Received for publication November 14, 2002, and accepted in revised form September 2, 2003.

Address correspondence to: Lisa Colletti, 2922G Taubman, Box 0331, 1500 East Medical Center Drive, Ann Arbor, Michigan 48109-0331, USA. Phone: (734) 936-7944; Fax: (734) 936-5830;

E-mail: colletti@umich.edu.

Conflict of interest: The authors have declared that no conflict of interest exists.

Nonstandard abbreviations used: macrophage inflammatory protein-2 (MIP-2); stem cell factor (SCF); murine IL-3 (mIL-3); mouse monocyte chemoattractant-1 (mMCP-1); phosphotyrosine signal transducer and activator of transcription (p-stat3).
While many of these molecules contribute to hepatic inflammation via direct effects, effects on the vascular endothelium, and/or neutrophil recruitment and activation, they have also been shown to be involved in hepatic repair and regeneration (3-13). This may be via direct actions and/or induction of additional factors that promote hepatocyte regeneration and repair $(3,4$, $8,10)$. Multiple studies have suggested that there is a complex regulatory system involved in hepatic regeneration following injury. Although many cytokines have proliferative effects on hepatocytes both in vitro and in vivo, no single molecule has been convincingly demonstrated to be the sole factor responsible for controlling hepatocyte proliferation in vivo. The regenerative and reparative process in the liver is exceedingly complex, having many layers. The requirement for multiple signals is likely critical in protecting the liver from undergoing compensatory hyperplasia in the absence of a compensatory need.

SCF is best known as a hematopoietic factor that is involved in the maturation and differentiation of multiple types of bone marrow-derived cells (14-17). Since the liver is a site of early hematopoietic activity, SCF may have effects in the fetal liver while hematopoiesis is occurring there. SCF is produced as a transmembrane protein that can be cleaved from the cell surface by enzymes released during inflammatory events, solubilizing the protein (14). While the proliferative and antiapoptotic effects of SCF are best described in bone marrow stem cells, these effects have also been noted in other cell types, including melanocytes (18-20). Recent data suggest that SCF may have a more generalized role in inducing cellular maturation and proliferation in a variety of cell types (21-24). Investigations have docu- 
mented significant hepatic SCF expression, possibly associated with hepatocyte proliferation (21-24). The current study investigates the possible role of SCF in hepatic regeneration following partial hepatectomy, both alone and in the context of IL-6-mediated hepatocyte proliferation.

\section{Methods}

Animal protocols and 70\% hepatectomy model. Six- to eightweek-old male CBA/J mice weighing approximately $20 \mathrm{~g}$ (The Jackson Laboratory, Bar Harbor, Maine, USA) were used in all experiments not using genetically altered knockout animals. SCF-deficient mice $(S l / S l d)$, IL-6 knockout mice ( $I L-6^{-/-}$mice), and their appropriate WT controls were also obtained from The Jackson Laboratory. Sl/Sld mice are "partial" SCF knockouts, i.e., are heterozygotes for the gene deletion; complete SCF knockout mice are very fragile animals that do not tolerate general anesthesia or laparotomy. Therefore, experiments were undertaken in the partial knockouts, which express very low SCF levels. All experiments were performed in compliance with the standards for animal use and care set by the University of Michigan's Committee on the Use and Care of Animals.

Anesthesia was induced with subcutaneous ketamine hydrochloride $(100 \mathrm{mg} / \mathrm{kg})$ and maintained with isoflurane inhalation. All animals received intraperitoneal lactated Ringer's solution $(40 \mathrm{ml} / \mathrm{kg})$ to replace intraoperative fluid and lost blood. Partial (70\%) hepatectomy was performed as previously described $(4,25)$. Briefly, 3-0 silk suture ligatures were secured around the base of the median and left lateral hepatic lobes and the lobes were resected. Sham-operated control animals were treated in an identical fashion with the omission of hepatectomy. Previous studies in mice in our laboratory have demonstrated that the liver will regain its appropriate weight (that is, have weight equal to that of sham-operated control animals of an equal age and body weight) approximately 7-9 days after $70 \%$ hepatectomy. Liver weight to total body weight ratios are used throughout this study; liver weights are expressed as a percentage of total body weight. Sl/Sld mice are generally smaller than their WT controls and also gain body weight after laparotomy more slowly than WT animals. Therefore, to correct for these differences in animal size, liver weight/body weight ratios are used instead of liver weights alone.

For the ELISA studies and Western blot analysis of whole cell lysates, animals were sacrificed in a kinetic fashion and liver and serum samples were obtained and snap frozen in liquid nitrogen until ready for analysis. For the liver weight/total body weight studies, animals were weighed immediately prior to sacrifice; after sacrifice, the liver was excised in toto, immediately weighed, and liver weight to total body weight ratios were calculated.

For the studies involving BrdU staining, animals were sacrificed in a kinetic fashion and liver tissue samples were obtained and processed for BrdU staining. Addi- tional in vivo studies were conducted in which the effects of exogenous SCF, exogenous IL-6, or anti-SCF antibody on hepatic regeneration were analyzed.

For the experiments using SCF, exogenous murine recombinant SCF (PeproTech Inc., Rocky Hill, New Jersey, USA) or vehicle (sterile PBS) administration was accomplished by bolus injection and chronic administration was performed using an Alzet pump release system (DURECT Corp., Cupertino, California, USA). The Alzet pumps function via an osmotic gradient, are implanted in the peritoneal cavity, and deliver $0.5 \mathrm{ml} / \mathrm{h}$ for up to 7 days. Cytokine dose is adjusted by altering the cytokine concentration within the pump reservoir. $\mathrm{Sl} / \mathrm{Sld}$ and $\mathrm{IL-6^{-/ }}$ mice received a dose of $1 \mu \mathrm{g} \mathrm{SCF} /$ mouse (each mouse weighed approximately $20 \mathrm{~g}$ ) at the time of operation as well as additional continuous SCF via the Alzet pump at a dose of $0.2 \mu \mathrm{g} / \mathrm{kg} / 24$ hours. Control animals received a similar regimen of vehicle at the same bolus dose and/or pump rate.

For the experiments involving administration of exogenous IL-6, recombinant murine IL-6 (PeproTech Inc.) was injected at a dose of $1 \mathrm{mg} / \mathrm{kg} 3$ hours prior to operation; this dose has been used in previously described experiments in the literature related to the hepatoproliferative effects of IL-6 (7). Control animals received an identical volume of vehicle.

For the experiments involving administration of antiSCF antibodies, WT animals or $\mathrm{Sl} / \mathrm{Sld}$ mice received a dose of $1 \mathrm{mg} / \mathrm{kg}$ anti-SCF antibody immediately postoperatively and then $1 \mathrm{mg} / \mathrm{kg}$ every 48 hours postoperatively until the time of sacrifice. This dosing schedule is dictated by previous antibody kinetic studies (4).

Production of anti-SCF, anti-IL-6, and control antibodies. Rabbit anti-murine SCF or anti-IL-6 antibodies were prepared by multiple-site immunization of $\mathrm{New}$ Zealand White rabbits with murine recombinant SCF or recombinant IL-6 (PeproTech Inc.) in CFA (4). Polyclonal antibodies were titered by direct ELISA and specifically verified by the failure to cross-react with a large panel of other cytokines, including murine IL-3 (mIL-3), mIL-1, mTNF- $\alpha$, mMIP-1 $\alpha$, epithelial neutrophil-activating protein, murine MIP-2, mouse monocyte chemoattractant-1 (mMCP-1), mMIP-1 $\beta$, human (h) monocyte chemotactic protein-1, hIL-8, hRANTES, hMIP- $1 \beta$, hTNF- $\alpha$, and hMIP- $1 \alpha$. The IgG portion of the serum was purified over a protein A column. The quality of the antibodies was assessed using in vitro assays consisting of blocking SCF-induced mast cell activation and migration, as previously described (26). The protein A column-purified IgG portion of the serum from nonimmunized rabbits was used as control antibody.

Primary hepatocyte isolation and culture. Primary hepatocyte isolation from mice was performed by collagenase perfusion as previously described (4). Briefly, general anesthesia is induced as described above, midline laparotomy is performed, the animal is heparinized $(150 \mathrm{U} / \mathrm{kg})$, and the portal vein is exposed and cannulated with a 26 -gauge angiocatheter. The liver is per- 
fused with HBSS $\left(\mathrm{Ca}^{+2}\right.$ - and $\mathrm{Mg}^{+2}$-free), $10 \mathrm{mM}$ HEPES, and $10^{5} \mathrm{U} / \mathrm{l}$ penicillin/streptomycin, $\mathrm{pH} 7.4$, at $37^{\circ} \mathrm{C}$ at a rate of $1 \mathrm{ml} / \mathrm{min}$ to flush the liver of intravascular blood. This step is followed by collagenase perfusion $\left(0.5 \mathrm{mg} / \mathrm{ml}\right.$ collagenase B in DMEM/F12 with $10^{5} \mathrm{U} / 1$ penicillin/streptomycin) at $37^{\circ} \mathrm{C}$ at a rate of $3 \mathrm{ml} / \mathrm{min}$ until tissue fracture is observed beneath the liver capsule. The liver is then removed to a Petri dish containing additional collagenase solution, the liver capsule is removed, and the tissue is gently agitated to disperse the cells. This solution is then filtered through sterile gauze into $25-\mathrm{ml}$ conical tubes and the total volume is brought to $25 \mathrm{ml}$ with DMEM/F12 with $10 \%$ FCS. This is then centrifuged at $360 \mathrm{rpm}$ at $4^{\circ} \mathrm{C}$ for 10 minutes and the pellet is resuspended in $1 \%$ DNase in DMEM/F12; this procedure is performed a total of three times. The cells are plated in Media 199 (BioWhittaker, Walkersville, Maryland, USA) with 10\% FCS, $10 \%$ horse serum, $10 \mathrm{mM}$ HEPES, $10^{5} \mathrm{U} / 1$ penicillin/streptomycin, $1.6 \mathrm{U} / \mathrm{l}$ insulin, and $4 \times 10^{-7} \mathrm{M}$ dexamethasone and incubated at $37^{\circ} \mathrm{C}$ under $5 \% \mathrm{CO}_{2}$. Hepatocyte viability is generally $85-95 \%$ as determined by trypan blue exclusion. Hepatocyte purity is determined by LDL staining, and typically the cells are $90-95 \%$ pure.

SCF ELISA. SCF was quantitated by ELISA using a modification of a double ligand method as previously described (4). Before each ELISA, snap-frozen liver tissue specimens were thawed on ice, weighed, and homogenized in a solution containing $2 \mathrm{mg} / \mathrm{ml}$ protease inhibitors (Complete; Roche Molecular Biochemicals, Indianapolis, Indiana, USA). Previous studies in our laboratories have shown that Complete protease inhibitors do not interfere with any of the chemokine or cytokine ELISAs. SCF levels were also measured in previously collected, frozen serum samples that were thawed immediately prior to performing ELISA.

For the in vitro studies measuring cellular production of SCF, cell-free supernatants were collected for the measurement of soluble SCF. Since SCF is found in both soluble and transmembrane forms, additional assays were performed to measure soluble plus bound, or soluble plus transmembrane SCF. For these measurements, both cells and supernatants were collected and sonicated so both forms of SCF could be measured. These samples were stored at $-70^{\circ} \mathrm{C}$ until the ELISAs were performed. All ELISA assays were performed in triplicate. For the animal studies, five animals per group per timepoint were used. In vitro studies were performed in triplicate and repeated a minimum of three times.

Flat-bottomed 96-well microtiter plates (Nunc Immuno-Plate I 96-F; Nunc A/S, Roskilde, Denmark) were coated with $50 \mu \mathrm{l} /$ well of mouse anti-SCF monoclonal antibody $\left(1 \mathrm{ng} / \mu \mathrm{l}\right.$ in $0.6 \mathrm{M} \mathrm{NaCl}, 0.26 \mathrm{M} \mathrm{H}_{3} \mathrm{BO}_{4}$, $0.08 \mathrm{~N} \mathrm{NaOH}, \mathrm{pH} 9.6)$ for 16 hours at $4^{\circ} \mathrm{C}$ and washed with PBS (pH 7.5) containing 0.05\% Tween-20 (wash buffer). Nonspecific binding sites were blocked with $2 \%$ BSA in PBS and incubated for 90 minutes at $37^{\circ} \mathrm{C}$. Plates were rinsed four times with wash buffer and diluted (1:2 and 1:10) cell-free supernatants or tissue homogenates in were added and followed by incubation for 1 hour at $37^{\circ} \mathrm{C}$; these experiments were performed in triplicate. Plates were again washed four times, followed by addition of $50 \mu \mathrm{l} /$ well biotinylated rabbit anti-SCF antibody (3.5 $\mathrm{ng} / \mu \mathrm{l}$ in PBS, $\mathrm{pH} 7.5$, $0.05 \%$ Tween-20, and $2 \%$ FCS) and incubation for 30 minutes at $37^{\circ} \mathrm{C}$. Plates were washed four times, streptavidin-peroxidase conjugate (Bio-Rad Laboratories Inc., Richmond, California, USA) was added, and plates were incubated for 30 minutes at $37^{\circ} \mathrm{C}$. Plates were again washed four times, chromogen substrate (BioRad Laboratories Inc.) was added, plates were incubated at room temperature to the desired extinction, and the reaction was terminated with $50 \mu \mathrm{l} /$ well of $3 \mathrm{M}$ $\mathrm{H}_{2} \mathrm{SO}_{4}$ solution. Plates were read at $490 \mathrm{~nm}$ in an ELISA reader. Standards were created with $1 / 2$ log dilutions of recombinant mSCF from $10 \mathrm{pg} / \mathrm{ml}$ to $100 \mathrm{ng} / \mathrm{ml}$. Measured SCF levels were normalized to tissue weight for the in vivo studies and expressed as ng/mg tissue, or per $\mathrm{ml}$ for the in vitro studies. This ELISA method consistently detects SCF concentrations above $250 \mathrm{pg} / \mathrm{ml}$. The SCF antibody ELISA did not cross-react with mIL-3, mIL-1, mTNF- $\alpha$, mMIP- $1 \alpha$, IL-6, mMCP-1, mMIP-1 $\beta$, human monocyte chemotactic protein-1, hIL-8, hRANTES, hMIP- $1 \alpha$, hTNF- $\alpha$, or hMIP- $1 \beta$.

In vitro measurement of hepatocyte DNA synthesis by ${ }^{3} \mathrm{H}$-thymidine incorporation. Measurement of in vitro proliferation of primary hepatocyte cell cultures was performed by incubation of cells in a 96-well plate for 18 hours with $0.5 \mu \mathrm{Ci}$ of ${ }^{3} \mathrm{H}$-thymidine (4). The cells were then harvested onto glass wool filters and ${ }^{3} \mathrm{H}$-thymidine incorporation was determined by liquid scintillation counting on a Beckman counter (Beckman Instruments Inc., Fullerton, California, USA). Each analysis was performed in triplicate and each experiment was repeated a minimum of three times.

In vivo measurement of hepatocyte DNA synthesis by BrdU incorporation. Two hours before sacrifice, animals were injected intraperitoneally with $30 \mathrm{mg}$ BrdU per g body weight. Animals were then sacrificed and liver specimens were obtained. Liver tissues were fixed in $4 \%$ paraformaldehyde for 24 hours, processed for histological analysis, and stained using the Amersham cell proliferation kit (Amersham Pharmacia Biotech, Hertfordshire, United Kingdom). Three animals were used per treatment group per timepoint, and five separate low-power fields were assessed per animal. The number of cells staining positively for BrdU per low-power field were counted and expressed as mean \pm SEM for each group.

Preparation of whole cell lysates. Frozen liver samples were thawed in prechilled lysis buffer $(100 \mathrm{mM}$ Tris, $0.1 \%$ SDS, $0.1 \%$ Triton X-100, and $15 \%$ glycerol), minced, homogenized, and sonicated. All tubes were maintained at $4^{\circ} \mathrm{C}$ and gently rotated on a rotator for 30 minutes and subsequently clarified through centrifugation at $14,000 \mathrm{~g}$ for 15 minutes at $4^{\circ} \mathrm{C}$. The supernatants were removed and centrifuged again at 14,000 $\mathrm{g}$ for $15 \mathrm{~min}$ utes at $4^{\circ} \mathrm{C}$. The resulting supernatants contained the total cell lysate proteins. Protein quantification was per- 

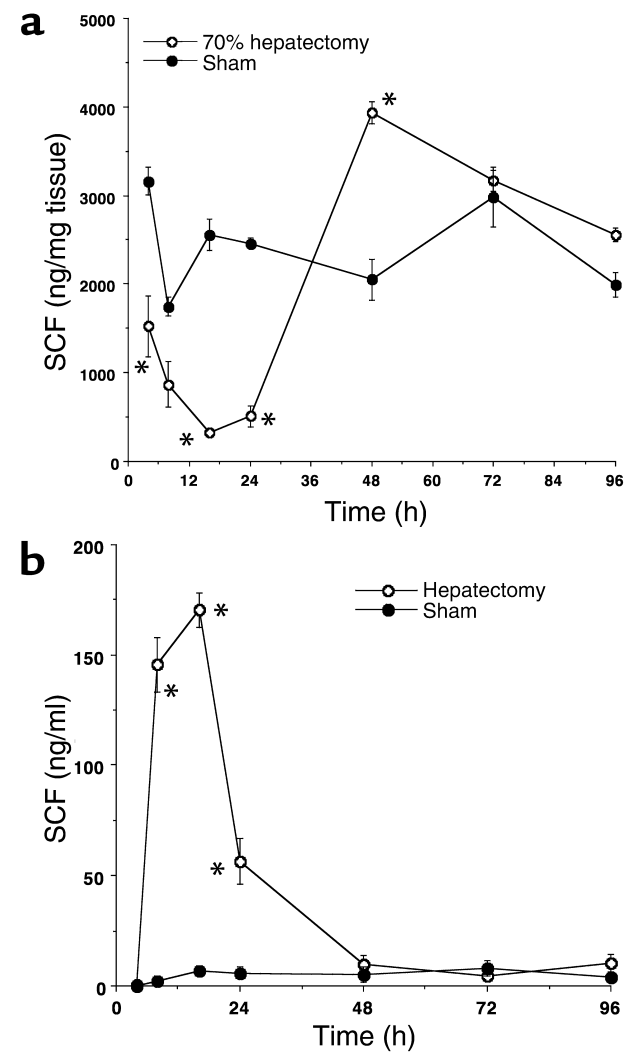

formed using a BCA protein assay kit (Pierce Biotechnology Inc., Rockford, Illinois, USA).

Western blot analysis. Sixty micrograms of total cell lysate were electrophoresed on a $12 \%$ polyacrylamide gel and then transferred to PVDF membranes (BioRad Laboratories Inc.). Membranes were blocked for 1 hour at room temperature in 5\% dry milk and were then incubated with primary antibody for phosphotyrosine signal transducer and activator of transcription (p-stat3) at 1:100 (all reagents were purchased from Santa Cruz Biotechnology Inc., Santa Cruz, California, USA). The antibodies were diluted in 5\% dry milk in Tris-buffered saline with $0.1 \%$ Tween- 20 and the membranes were incubated with the antibodies overnight. The appropriate secondary antibodies in a dilution of 1:5,000 were then added and incubation continued for 1 hour at room temperature. The same blots were also stripped and reanalyzed using anti-GAPDH monoclonal antibodies (Chemicon International Inc., Temecula, California, USA) as an internal protein loading control. Antigen-antibody complexes were detected with the enhanced chemiluminescence detection system (ECL; Amersham Pharmacia Biotech, Piscataway, New Jersey, USA).

Statistical analysis. The in vivo studies used five mice in each group at each timepoint (27). For Western blot analysis, each experiment was repeated a minimum of three times and representative gels are shown; densitometry graphs represent the mean densitometry values for three separate gels from three separate animal

\section{Figure 1}

Hepatic and serum SCF levels after partial hepatectomy. Animals underwent $70 \%$ hepatectomy or sham laparotomy and liver tissue and serum was obtained for SCF quantitation by ELISA at various times postoperatively. Hepatic tissue SCF levels were normalized to tissue weight and expressed as $\mathrm{ng} / \mathrm{mg}$ tissue. Serum SCF levels were expressed as $\mathrm{ng} / \mathrm{ml}$. Sham-operated control animals demonstrated high constitutive levels of hepatic SCF, in the range of 2,000-3,000 $\mathrm{ng} / \mathrm{mg}$ tissue, and low serum SCF content. (a) Following 70\% hepatectomy, hepatic SCF levels initially drop, then increase to supranormal levels 24-48 hours after hepatectomy, and then gradually drop to baseline levels. (b) In contrast, following 70\% hepatectomy, serum SCF levels initially increase significantly, concurrent with the drop that is seen in hepatic SCF levels, then subsequently gradually decline to baseline levels. This suggests that bound hepatic SCF may be cleaved into the soluble form and released into the systemic circulation in response to hepatectomy. ${ }^{*} P<0.05$ vs. sham-operated control animals. Data is expressed as mean \pm SEM.

groups. Groups of data were evaluated by ANOVA and Student-Newman-Keuls tests to identify significant differences (26). Differences were considered significant if $P$ values were less than 0.05 . Results are presented as mean \pm SEM. Data was analyzed using a PowerPC 7100 computer using the StatView II statistical software package (Abacus Concepts Inc., San Francisco, California, USA).

\section{Results}

Hepatic SCF following partial hepatectomy. Animals underwent $70 \%$ hepatectomy or sham laparotomy and were sacrificed at 4, 8, 16, 24, 48, 72, and 96 hours after operating. Liver and serum samples were obtained and were analyzed for SCF content by ELISA. Hepatic SCF levels were normalized to tissue weight, with SCF levels being expressed as $\mathrm{ng} / \mathrm{mg}$ tissue; serum SCF levels were expressed as $\mathrm{ng} / \mathrm{ml}$. Sham-operated control animals demonstrated high constitutive levels of SCF in the liver, measuring in the range of $2,000-3,000 \mathrm{ng} / \mathrm{mg}$ tissue (Figure 1a), suggesting a large baseline hepatic reservoir of SCF. Sham-operated control animals have low serum SCF levels (Figure 1b). Following partial hepatectomy, there is a significant decline in hepatic SCF levels during the first 24 hours after hepatectomy (Figure 1a). Concurrent with this decline in hepatic SCF levels, there is a significant increase in serum SCF levels (Figure 1b), possibly suggesting that bound hepatic SCF is being cleaved into the soluble form in response to hepatectomy. This initial decline in hepatic SCF levels is followed by a significant rebound to supranormal levels 24-48 hours after hepatectomy, with a subsequent gradual decline to baseline over time (Figure 1a). Similarly, serum SCF levels decline concurrent with the increase in hepatic levels (Figure 1b).

In vitro analysis of hepatocyte response to SCF. The next experiments investigated SCF's effects on primary mouse hepatocytes in vitro. Primary hepatocytes were exposed to media alone or $1,10,25,50$, or $100 \mathrm{ng} / \mathrm{ml}$ of SCF, and proliferation was measured at 24 and 48 hours by incorporation of ${ }^{3} \mathrm{H}$-thymidine. Exposure 


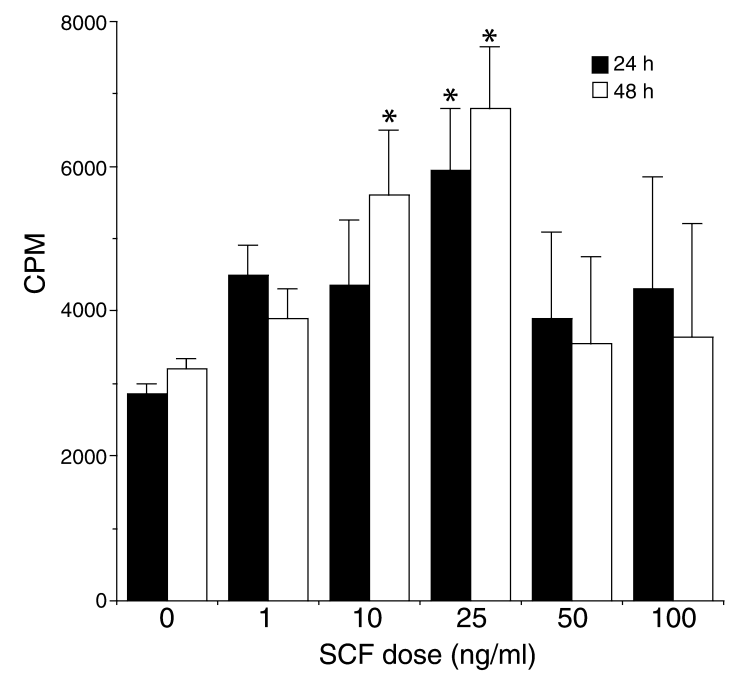

Figure 2

Primary mouse hepatocyte proliferation in vitro in response to SCF. Primary mouse hepatocytes were exposed to increasing doses of SCF from 0 to $100 \mathrm{ng} / \mathrm{ml}$ and proliferation was measured after 24 and 48 hours of incubation. SCF treatment resulted in a significant increase in hepatocyte proliferation at the 10 and $25 \mathrm{ng} / \mathrm{ml}$ doses. Interestingly, the higher doses of SCF did not result in a significant increase in hepatocyte proliferation. Data are expressed as mean \pm SEM. ${ }^{*} P<0.05$ vs. media alone at the same timepoint.

to 10 and $25 \mathrm{ng} / \mathrm{ml} \mathrm{SCF}$ resulted in a significant increase in primary hepatocyte proliferation compared with incubation with media alone (Figure 2). Interestingly, the higher doses of SCF did not have a significant proliferative effect.

Stimuli for SCF production and release. Since prior investigations have suggested that SCF may be produced in response to sepsis (28), we were next interested in determining whether IL- 6 could stimulate SCF production and release. Primary mouse hepatocytes in vitro were stimulated with $20 \mathrm{ng} / \mathrm{ml} \mathrm{IL}-6$ or media alone and were harvested after 1, 2, 4, 8, 12, and 24 hours of incubation. Supernatants or supernatants plus cells were collected for SCF measurement by ELISA. Supernatant levels of SCF were used to estimate levels of soluble SCF; for quantitation of soluble plus bound SCF, supernatants plus cells were sonicated and SCF levels in this solution were used as an estimate of soluble plus bound SCF. Primary mouse hepatocytes produce significant amounts of both soluble and soluble plus bound SCF in response to IL-6 at all timepoints studied (Figure 3).

Since IL-6 is a known hepatocyte mitogen and since the above experiments suggest that IL- 6 can induce SCF production and release, the next experiments were designed to investigate whether SCF- and IL-6-induced hepatocyte proliferation occurs via a related pathway. At a dose of $20 \mathrm{ng} / \mathrm{ml}$, both IL-6 and SCF induced significant hepatocyte proliferation after 24 hours of incubation, as measured by incorporation of ${ }^{3} \mathrm{H}$-thymidine (Figure 4). Next, the effects of IL-6 or SCF blockade in the presence of SCF or IL-6, respectively, were measured. When hepatocytes were incubated with 20 $\mathrm{ng} / \mathrm{ml} \mathrm{SCF}$ plus anti-IL- 6 antibody $(10 \mu \mathrm{g} / \mathrm{l})$, a slight decrease in hepatocyte proliferation was observed, although this did not reach statistical significance (Figure 4). In contrast, when cells were incubated with 20 $\mathrm{ng} / \mathrm{ml} \mathrm{IL}-6$ plus anti-SCF antibody $(10 \mu \mathrm{g} / \mathrm{l})$, a significant decrease in proliferation was noted, suggesting that SCF plays a role in IL-6-induced hepatocyte proliferation in this system (Figure 4).

In vivo SCF effects after partial hepatectomy. Following $70 \%$ hepatectomy, hepatic SCF levels initially decline, then rebound to supranormal levels; in vitro, SCF appears to be a hepatocyte mitogen. Therefore, the next experiments studied SCF's potential role as an in vivo hepatic mitogen following partial hepatectomy. Mice underwent $70 \%$ hepatectomy, were treated with antiSCF antibody or control antibody, and liver weight/ total body weight ratios were determined 7 days postoperatively as an estimate of hepatic regeneration. Table 1 illustrates a significant decrease in liver weight/ total body weight ratios in mice treated with anti-SCF antibody compared with mice treated with control antibody. Next, additional kinetic experiments were

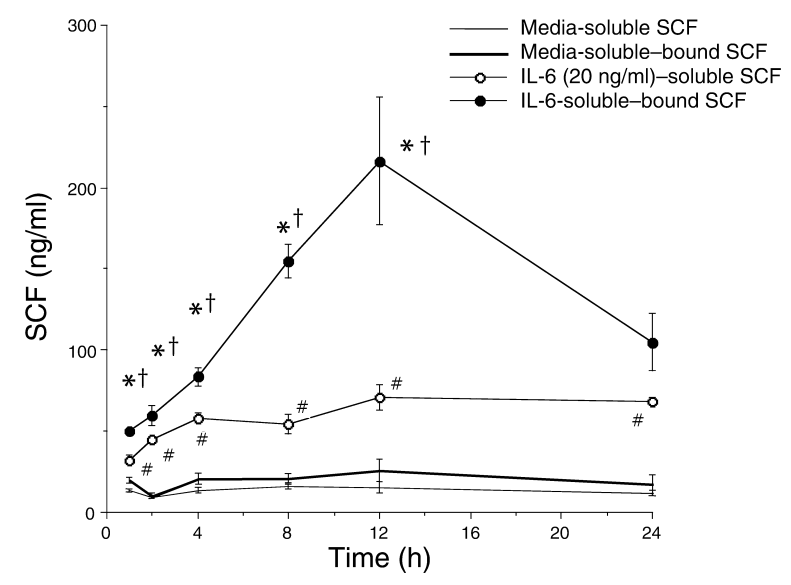

Figure 3

In vitro primary mouse hepatocyte SCF production in response to IL-6. Primary mouse hepatocytes were stimulated with $20 \mathrm{ng} / \mathrm{ml} \mathrm{IL-6}$ or media alone. Supernatants and supernatants plus cells were harvested at various timepoints and SCF levels were measured by ELISA. Supernatant SCF levels were used to determine levels of soluble SCF. For quantitation of soluble + bound SCF, supernatants plus cells were sonicated and SCF levels in this solution were measured as an estimate of soluble + bound SCF. There were no significant differences noted in levels of soluble compared with soluble + bound SCF in cells incubated in media alone. There were significant increases in soluble SCF levels at all timepoints from cells treated with IL- $6\left({ }^{\#} P<0.05\right.$ vs. media alone). In addition, levels of soluble + bound SCF were significantly increased after IL-6 treatment compared with treatment with media alone ( ${ }^{*} P<0.01$ vs. media alone). Furthermore, levels of soluble plus bound SCF were significantly increased compared with levels of soluble SCF alone after IL- 6 treatment at all timepoints $\left({ }^{\dagger} P<0.05\right.$ vs. soluble levels). Data are expressed as the mean \pm SEM. Thin line, cells incubated with media alone and assayed for soluble SCF; heavy line, cells incubated with media alone and assayed for soluble and bound SCF; open circles, cells stimulated with IL-6 $(20 \mathrm{ng} / \mathrm{ml})$ and assayed for soluble SCF; closed circles, cells stimulated with IL-6 (20 $\mathrm{ng} / \mathrm{ml}$ ) and assayed for soluble plus bound SCF. 


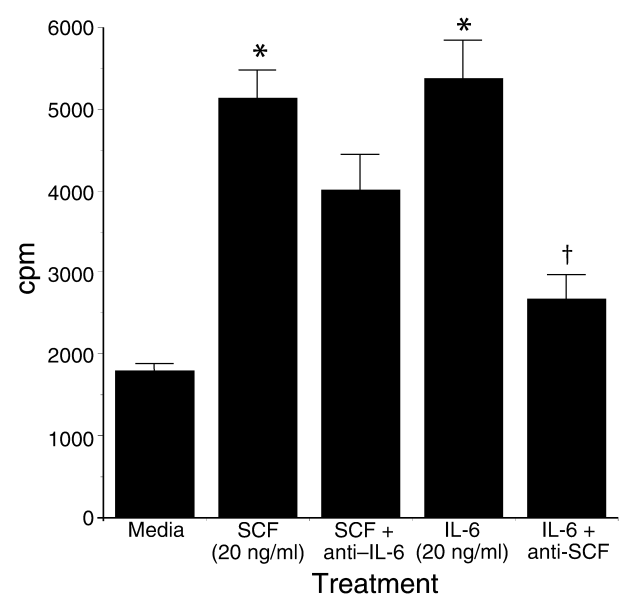

\section{Figure 4}

In vitro primary mouse hepatocyte proliferation in response to SCF or IL- 6 with and without treatment with anti-IL- 6 or anti-SCF. Treatment of primary mouse hepatocytes with IL- 6 or SCF alone resulted in a significant increase in hepatocyte proliferation after 24 hours of incubation ( ${ }^{*} P<0.05$ vs. media alone). Next, cells were treated with SCF and anti-IL- 6 antibody; this treatment did not result in a significant change in hepatocyte proliferation. In contrast, when cells were treated with IL- 6 and anti-SCF antibody, a significant decrease in hepatocyte proliferation was observed ( ${ }^{\dagger} P<0.05$ vs. IL- 6 and SCF alone). Data are expressed as mean \pm SEM.

performed in which hepatocyte proliferation following partial hepatectomy and treatment with anti-SCF antibody or control antibody was measured with BrdU staining. As illustrated in Figure 5a, treatment with anti-SCF in the context of partial hepatectomy results in a significant decrease in hepatocyte proliferation, as measured by BrdU incorporation, at 48 and 60 hours after hepatectomy. Furthermore, there is a significant increase in BrdU staining at 72 hours after hepatectomy, suggesting that decreases in SCF result in a delay in hepatocyte proliferation, rather than completely preventing proliferation (Figure 5a).

Since SCF blockade after partial hepatectomy decreased hepatic regrowth as estimated by liver weight/total body weight ratios and BrdU staining, the next experiments investigated the rate of hepatic regrowth in $\mathrm{Sl} / \mathrm{Sld}$ mice following $70 \%$ hepatectomy, again by measuring liver weight to total body weight ratios and hepatic BrdU staining. Table 2 shows that there is a significant decrease in liver weight/total body weight ratios in the $S l / S l d$ mice compared with WT mice 7 days after hepatectomy. If exogenous SCF is administered to $\mathrm{Sl} / \mathrm{Sld}$ mice after partial hepatectomy, liver weight/total body weight ratios are restored to near-normal 7 days after hepatectomy (Table 3), suggesting that SCF is important for hepatic regeneration in this model.

These data are substantiated by BrdU staining in similar experiments. Mice underwent $70 \%$ hepatectomy and were sacrificed at $24,36,48,60$, and 72 hours postoperatively, and liver tissue was obtained for BrdU staining. Figure $5 \mathrm{~b}$ illustrates BrdU staining in $\mathrm{Sl} / \mathrm{Sld}$ mice and WT control mice. These experiments show that hepatocytes proliferate at a slower rate in $\mathrm{Sl} / \mathrm{Sld}$ mice than in WT mice after partial hepatectomy; BrdU staining is significantly decreased at 48 and 60 hours after hepatectomy. Interestingly, BrdU staining is significantly increased at 72 hours after hepatectomy in the $\mathrm{Sl} / \mathrm{Sld}$ mice, suggesting that lack of SCF slows but does not eliminate hepatocyte proliferation. Treatment of $\mathrm{Sl} / \mathrm{Sld}$ mice with exogenous SCF restores hepatocyte proliferation to near-normal. Figure $5 c$ demonstrates that there is no difference in hepatocyte proliferation following partial hepatectomy between WT mice treated with SCF, WT mice treated with vehicle, and Sl/Sld mice treated with SCF. In contrast, $S l / S l d$ mice treated with vehicle and partial hepatectomy had a significant decrease in BrdU staining at 48 and 60 hours after hepatectomy. While there was an increase in BrdU staining in WT mice treated with SCF and hepatectomy, these results did not reach statistical significance. These experiments suggest that a lack of SCF slows hepatocyte proliferation and hepatic regeneration following hepatic resection.

Relationship between SCF and IL-6 in vivo. Our in vitro data suggests that IL-6-induced hepatocyte proliferation may involve SCF. Therefore, the next experiments investigated the effects of SCF administration to IL-6 knockout mice following partial hepatectomy. Figure 6a illustrates liver weight/total body weight ratios in WT and IL-6 knockout mice following partial hepatectomy with and without exogenous SCF administration. Particularly at the later timepoints, SCF administration to IL-6 knockout mice restored liver weight/total body weight ratios to near-normal (Figure 6a). Figure 6a illustrates the kinetics of this response over time. Beginning 3 days postoperatively and continuing to 5 days postoperatively, significant differences in liver weight/total body weight ratios are seen between IL-6 knockout mice treated with vehicle compared with IL- 6 knockout mice treated with exogenous SCF.

The above liver weight/total body weight ratio data suggests that SCF replacement in IL-6 knockout mice restores hepatic regeneration to near-normal. To further investigate these effects, BrdU staining was performed on WT and IL-6 knockout animals undergoing partial hepatectomy with and without SCF treatment. These results are demonstrated in Figure 6b. This graph suggests that SCF administration to IL-6 knock-

\section{Table 1}

Liver weight/body weight ratios in mice undergoing $70 \%$ hepatectomy and anti-SCF antibody treatment

\begin{tabular}{cccc}
\hline Sham & $70 \%$ Hep & $\begin{array}{c}70 \% \text { Hep }+ \\
\text { anti-SCF }\end{array}$ & $\begin{array}{c}70 \% \text { Hep + } \\
\text { control Ab }\end{array}$ \\
$6.03 \% \pm 0.27 \%$ & $5.23 \% \pm 0.27 \%$ & $4.17 \% \pm 0.19 \%^{\mathrm{A}}$ & $5.27 \% \pm 0.20 \%$
\end{tabular}

Control animals received antibody without SCF blocking properties. Animals were sacrificed on posthepatectomy day 7 . Data are expressed as mean \pm SEM Five animals were used per group. ${ }^{A} P<0.05$ vs. $70 \%$ hepatectomy, $70 \%$ hepatectomy + control antibody, and sham. Hep, hepatectomy. 

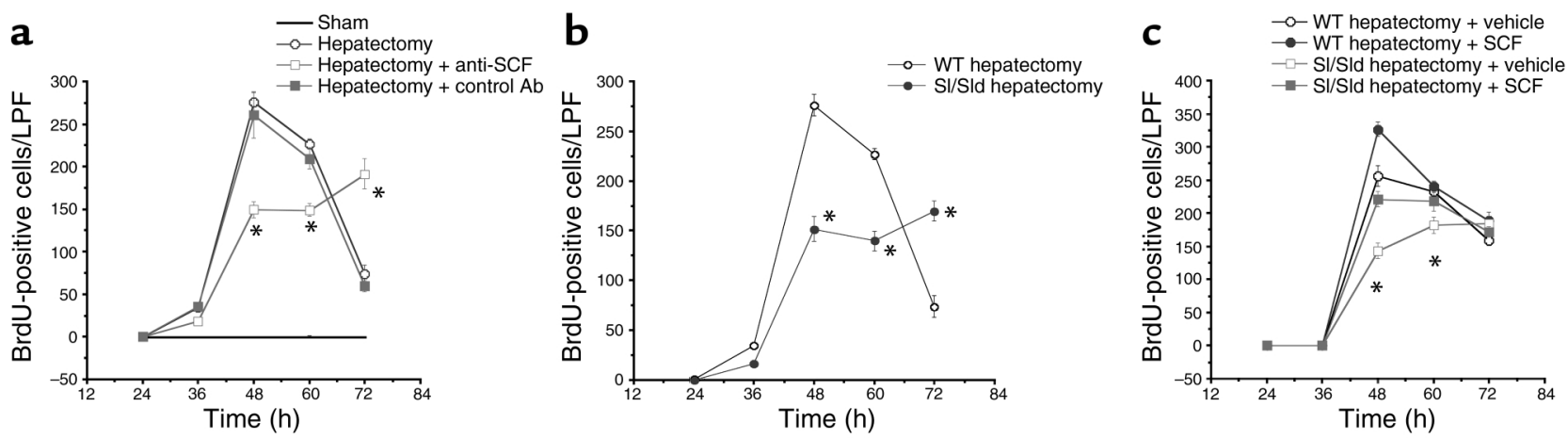

\section{Figure 5}

BrdU staining following partial hepatectomy in (a) mice treated with anti-SCF or control antibody; (b) SI/SId or WT mice; and (c) Sl/Sld or WT mice treated with SCF or vehicle. Mice underwent $70 \%$ hepatectomy, and BrdU staining was used as an estimate of hepatocyte proliferation. The effects of anti-SCF or control antibody after partial hepatectomy are shown in a. Anti-SCF antibody treatment resulted in a significant decrease in hepatocyte proliferation at 48 and 60 hours after hepatectomy $\left({ }^{*} P<0.05\right.$ vs. hepatectomy alone and hepatectomy plus control antibody). Interestingly, there is a significant rise in BrdU staining in anti-SCF-treated animals at 72 hours after hepatectomy, suggesting that blockade of SCF effects results in a delay in proliferation, although proliferation is not completely prevented $\left({ }^{*} P<0.05 \mathrm{vs}\right.$. hepatectomy alone and hepatectomy plus control antibody). The effects of hepatectomy in SI/SId or WT mice are illustrated in $\mathbf{b}$. WT animals have significantly increased levels of hepatocyte proliferation compared with SI/SId mice, particularly at 48 and 60 hours after hepatectomy. SI/SId mice did demonstrate increasing proliferation at 72 hours postoperatively, suggesting that some rebound in proliferation was occurring. ( ${ }^{*} P<0.05$ vs. WT). The effects of exogenous SCF administration on SI/SId or WT mice after $70 \%$ hepatectomy are illustrated in $c$. SCF administration to WT animals had minimal effects; in contrast, SCF administration to SI/S/d mice restored hepatocyte proliferation to nearnormal. ${ }^{*} P<0.05$ vs. WT mice treated with vehicle, WT mice treated with SCF, and SI/SId mice treated with SCF. LPF, low power field.

out mice after partial hepatectomy results in an earlier and larger induction of hepatocyte proliferation than is seen in IL-6 knockout animals undergoing hepatectomy and treatment with vehicle. In IL- 6 knockout mice subjected to hepatectomy and SCF treatment, hepatocyte proliferation is significantly increased at 36 hours compared with IL-6 knockout mice treated with hepatectomy and vehicle, WT mice undergoing hepatectomy and vehicle treatment, and WT mice undergoing hepatectomy and SCF administration (Figure 6b). At 48 hours, there is no significant difference in proliferation between IL-6 knockouts treated with SCF, WT mice treated with SCF, or WT mice treated with vehicle (Figure 6b). In contrast, at 48 hours, IL-6 knockouts treated with vehicle have significantly less proliferation than the other three groups at this timepoint (Figure $6 \mathrm{~b})$. At 60 hours, IL-6 knockouts treated with vehicle still have significantly less proliferation than WT mice treated with vehicle or SCF; however, at 60 hours there is no difference between IL- 6 knockouts treated with vehicle and IL-6 knockouts treated with SCF (Figure $6 \mathrm{~b})$. This suggests that proliferation is accelerated in IL-6 knockouts treated with SCF and is nearly completed by 60 hours.

In order to further study the relationships between IL-6 and SCF following partial hepatectomy in vivo, additional experiments were performed in which IL-6 was administered to $\mathrm{Sl} / \mathrm{Sld}$ mice in the context of partial hepatectomy. Administration of IL- 6 did not enhance hepatocyte proliferation in either WT or Sl/Sld mice (Figure 7), and in fact, decreased proliferation somewhat, although this did not reach statistical significance. BrdU staining in $\mathrm{Sl} / \mathrm{Sld}$ mice treated with vehicle or IL-6 was significantly decreased at 48 and 60 hours compared with WT mice treated with vehicle or IL-6. There was no difference in BrdU staining at 72 hours between either the WT group or $S l / S l d$ mice treated with vehicle; in contrast, BrdU staining in Sl/Sld mice treated with IL- 6 was significantly decreased compared with the other three groups 72 hours postoperatively. This data was confirmed by liver weight/total body weight ratios that were obtained 7 days postoperatively (Table 4). These data demonstrated that liver weight/total body weight ratios in $\mathrm{Sl} / \mathrm{Sld}$ mice undergoing hepatectomy plus vehicle treatment are significantly smaller than those seen in WT mice treated with IL-6 or vehicle in the context of hepatectomy. There was no significant difference seen in the liver weight/total body weight ratios in WT mice undergoing hepatectomy plus IL-6 treatment compared with WT mice undergoing hepatectomy plus vehicle treatment (Table 4). Similarly, there were no significant differences seen in $S l / S l d$ mice undergoing hepatectomy plus vehicle treatment compared with $S l / S l d$ mice undergoing hepatectomy plus IL-6 (Table 4).

\section{Table 2}

Liver weight/body weight ratios in WT and SI/S/d mice undergoing $70 \%$ hepatectomy

$\begin{array}{lcr} & \text { Sham } & 70 \% \text { Hepatectomy } \\ \text { SI/SId mice } & 5.22 \pm 0.02 \% & 4.77 \pm 0.05 \%{ }^{\mathrm{A}} \\ \text { WT } & 5.64 \pm 0.53 \% & 5.63 \pm 0.01 \%\end{array}$

Animals were sacrificed on postoperative day 7. Data are expressed as mean \pm SEM. Five animals were used per group. ${ }^{A} P<0.05$ vs. Sl/SId sham, WT sham, and WT hepatectomy. 


\section{Table 3}

Liver weight/body weight ratios in WT and SI/SId mice undergoing $70 \%$ hepatectomy and treatment with exogenous SCF or vehicle.

$\begin{array}{lcc} & \text { WT } & \text { SI/SId } \\ 70 \% \text { Hep + vehicle } & 5.5+0.1 \% & 4.73+0.3 \% \\ 70 \% \text { Hep + SCF } & 5.45+0.05 \% & 5.1+0.1 \%{ }^{\mathrm{A}}\end{array}$

Animals were sacrificed on postoperative day 7. Data are expressed as mean \pm SEM. Five animals were used per group. ${ }^{*} P<0.05$ vs. Sl/S/d mice undergoing $70 \%$ hepatectomy treated with vehicle.

Enhanced hepatocyte proliferation in response to SCF in IL-6 knockout mice is stat3-mediated. Prior investigations have documented that IL-6-induced hepatocyte proliferation following hepatectomy occurs via a stat3-mediated pathway $(7,9,13)$. Since our current data suggests that SCF may be involved in this pathway, we next investigated whether the SCF-induced increases in hepatocyte proliferation in IL- 6 knockout mice were stat3-mediated. Figure 8 illustrates a representative Western blot for cytosolic p-stat3. The densitometric analysis of three separate Western blots from three different animals is also shown. These experiments demonstrate that there is a significant decrease in cytosolic p-stat3 levels in IL-6 knockout mice at 1 and 3 hours after hepatectomy compared with WT controls. Furthermore, treatment of IL-6 knockout mice with SCF following hepatectomy restores cytosolic p-stat3 levels to those of WT controls, that is, there was no significant difference between cytosolic p-stat 3 levels in IL-6 knockout mice receiving SCF after hepatectomy versus WT controls after hepatectomy; p-stat3 levels in IL-6 knockout mice receiving SCF and hepatectomy were significantly increased compared with IL-6 knockout mice undergoing hepatectomy alone. In addition, WT mice treated with SCF in the setting of partial hepatectomy had significantly increased cytosolic p-stat3 levels compared with WT animals undergoing hepatectomy alone. SCF's effects on p-stat 3 occurred at early timepoints after partial hepatectomy. No effects on p-stat 3 levels were seen at later timepoints (after 6 hours; data not shown).

Investigation of stat3 involvement during in vitro bepatocyte proliferation in response to SCF and IL-6. Previous investigations have documented that IL-6-induced hepatocyte proliferation is mediated via a stat 3 signal transduction pathway $(7,9,13)$. In order to further document SCF's involvement in IL-6-mediated hepatocyte proliferation, additional in vitro experiments using primary mouse hepatocytes were performed. For the initial experiments, hepatocytes were incubated with media alone or 1,10 , or $50 \mathrm{ng} / \mathrm{ml}$ of SCF or IL-6. Cells were harvested after 1, 3, or 6 hours of incubation and cytosolic p-stat 3 levels were measured by Western blot analysis. Figure 9 shows representative Western blots from these experiments. As has been previously shown, IL-6-induced hepatocyte proliferation is mediated via stat3, and as illustrated in Figure 9, cytosolic p-stat 3 levels are increased compared with media alone at 1, 3, and 6 hours after stimulation $(7,9,13)$. Figure 9 also demonstrates similar increases in cytosolic p-stat 3 in response to hepatocyte stimulation with SCF, suggesting that SCF-induced hepatocyte proliferation is also occurring via a stat3-mediated pathway.

In order to further study the relationship between SCF and IL- 6 in the context of hepatocyte proliferation, cells were stimulated with 1,10 , or $50 \mathrm{ng} / \mathrm{ml} \mathrm{IL}-6$ and $10 \mu \mathrm{g} / 1$ anti-SCF or with 1,10 , or $50 \mathrm{ng} / \mathrm{ml} \mathrm{SCF}$ and $10 \mu \mathrm{g} / \mathrm{l}$ anti-IL-6. Since we have postulated that IL-6mediated hepatocyte proliferation is SCF-dependent, these additional in vitro experiments were designed to further dissect this pathway. Figure 10 illustrates representative Western blots from these experiments. SCF blockade in the setting of IL-6-induced hepatocyte proliferation results in decreased cytosolic levels of p-stat 3 (Figure 10). In contrast, IL-6 blockade in the setting of
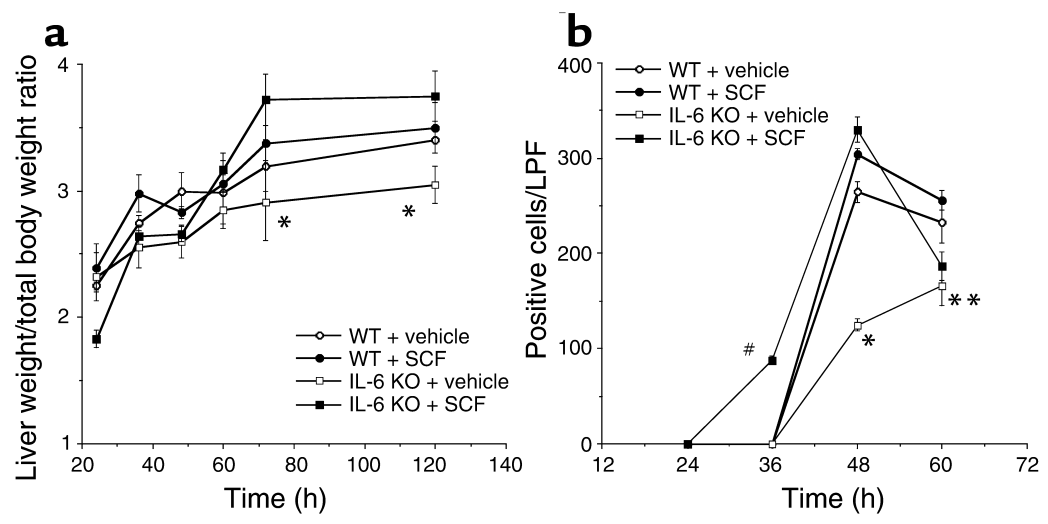

Figure 6

Liver weight/total body weight ratios and BrdU staining in WT and IL-6 knockout mice after $70 \%$ hepatectomy with and without SCF treatment. Liver weight/total body weight ratios and BrdU staining as an estimate of hepatocyte proliferation were measured in mice over time. Four treatment groups were studied: WT + vehicle, WT + SCF, IL-6 knockout + vehicle, and IL-6 knockout + SCF. (a) Beginning 72 hours after hepatectomy, liver weight/total body weight ratios in IL-6 knockout mice treated with vehicle are significantly decreased compared with the other three treatment groups, and this difference continues to 120 hours. ${ }^{*} P<0.05$, IL- 6 knockout + vehicle vs. all other groups. There was no significant difference noted between IL-6 knockout mice treated with SCF and WT animals treated with vehicle or SCF. Data are expressed as mean \pm SEM. (b) At 36 hours after hepatectomy, there was a significant increase in hepatocyte proliferation in IL-6 knockout animals treated with SCF ( $P<0.05$ vs. all other treatment groups). At 48 hours of incubation, the proliferation measured in IL-6 knockout animals treated with vehicle was significantly decreased compared with all other treatment groups ( ${ }^{*} P<0.01$ vs. all other groups). By 60 hours after hepatectomy, proliferation in IL-6 knockout mice treated with vehicle was still significantly decreased compared with WT animals treated with vehicle or SCF $(* * P<0.05$ vs. WT + vehicle and WT + SCF); however, there was no longer a difference between IL- 6 knockout mice treated with vehicle and IL-6 knockout mice treated with SCF. 


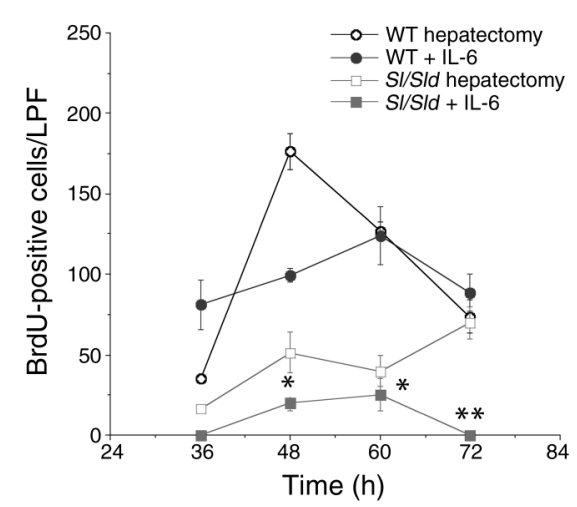

SCF-induced hepatocyte proliferation results in minimal decreases in cytosolic p-stat 3 levels (Figure 10). This suggests that IL-6-induced hepatocyte proliferation is at least partially mediated via upregulation of SCF and that SCF-induced hepatocyte proliferation is stat3-mediated.

\section{Discussion}

The current studies suggest that the healthy liver harbors a significant reservoir of SCF. Both our in vivo and in vitro experiments also suggest that SCF functions as a hepatic mitogen and that this may occur via an IL-6-mediated pathway, with SCF functioning downstream of IL-6. SCF is produced as a transmembrane protein that can be cleaved from the cell surface by enzymes released during inflammatory events, solubilizing the protein (14). Previous studies have shown that partial hepatectomy incites an inflammatory response

\section{Figure 8}

Representative Western blot and associated densitometric analysis for cytosolic p-stat 3 levels in WT and IL- 6 knockout mice undergoing hepatectomy with and without SCF treatment. The Western blot is a single representative blot from one group of animals. The graph demonstrates densitometric analysis of three separate Western blots from three groups of animals. The maximum OD for each well was normalized to the maximum OD for the same well for GAPDH to correct for slightly unequal protein loading. The mean and standard errors were then calculated for each group and statistical analysis was performed. These experiments demonstrated that there is a significant decrease in cytosolic p-stat 3 levels in IL- 6 knockout mice treated with vehicle at 1 and 3 hours after hepatectomy compared with WT animals undergoing hepatectomy and treatment with vehicle $\left({ }^{*} P<0.05\right.$, IL- 6 knockout mice + vehicle vs. all other treatment groups at that timepoint). Furthermore, treatment of IL- 6 knockout mice with SCF restores cytosolic p-stat3 levels to those of WT animals treated with vehicle, that is, there was no significant difference between cytosolic $p$-stat 3 levels in IL-6 knockout mice receiving SCF after hepatectomy vs. WT animals undergoing hepatectomy; $\mathrm{p}$-stat 3 levels in IL-6 knockout mice receiving SCF and hepatectomy were significantly increased compared with IL- 6 knockout mice undergoing hepatectomy alone. In addition, treatment of WT mice with SCF in the setting of partial hepatectomy significantly increased cytosolic p-stat 3 levels in these animals compared with WT animals undergoing hepatectomy alone. ${ }^{\# P}<0.05, \mathrm{WT}+\mathrm{SCF}$ vs. WT + vehicle at the same timepoint.

\section{Figure 7}

BrdU staining following partial hepatectomy in SI/SId or WT mice treated with IL-6 or vehicle. SI/SId or WT mice were subjected to $70 \%$ hepatectomy with and without treatment with exogenous IL-6. Four treatment groups were studied: WT + vehicle, WT + IL-6, SI/SId + vehicle, and SI/SId + IL-6. Administration of IL- 6 to WT animals had minimal effects, as did IL- 6 administration to $S I / S / d$ mice. $\left({ }^{*} P<0.05\right.$ for $S I / S / d+$ vehicle and SI/SId + IL-6 vs. WT + vehicle and WT + IL-6; ${ }^{*} P<0.05$ for $S I / S I d+I L-6$ vs. all other groups).

(29), and SCF cleavage is likely a part of this inflammatory event. This is also suggested by our studies, which show that at early timepoints following partial hepatectomy, there is a decline in hepatic SCF levels concurrent with increased serum levels, suggesting that hepatectomy results in cleavage of bound hepatic SCF into its soluble form. Some studies suggest a differential activity for the membrane-bound versus the soluble form of SCF (30). Both soluble and transmembrane SCF can activate leukocyte populations (14). For example, SCF enhances eosinophil-endothelial adherence by increasing the affinity of VLA-4 for VCAM-1 (31). SCF has also been noted to have proliferative and antiapoptotic effects in other cell types, including melanocytes and bone marrow stem cells (18-20). The data presented here support results from other recent investigations that have demonstrated significant hepatic SCF expression associated with hepatocyte growth and regulation (21-24).

IL-6 is an important inflammatory cytokine that also induces hepatocyte proliferation; this process is mediated through stat $3(7,9,13)$. Studies by Clavien and col-

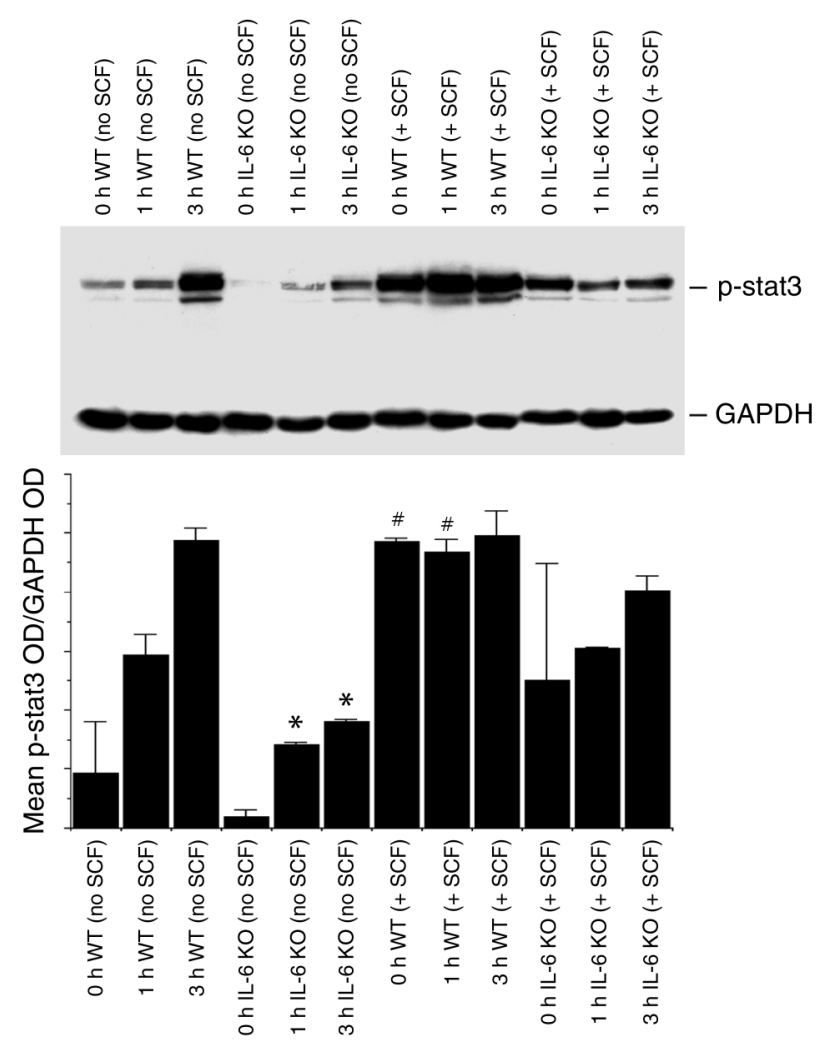




\section{Table 4}

Liver weight/body weight ratios in WT and SI/S/d mice undergoing 70\% hepatectomy and treatment with exogenous IL-6 or vehicle

\begin{tabular}{lcc}
\hline & WT & SI/SId \\
$70 \%$ Hep + vehicle & $4.5 \pm 0.1 \%$ & $3.83 \pm 0.3 \%^{\mathrm{A}}$ \\
$70 \%$ Hep + IL-6 & $4.13 \pm 0.15 \%$ & $3.91 \pm 0.9 \%^{\mathrm{B}}$
\end{tabular}

Animals were sacrificed on postoperative day 7. Data are expressed as mean \pm SEM. Five animals were used per group. ${ }^{A} P<0.05$ vs. WT mice undergoing $70 \%$ hepatectomy + vehicle treatment or $70 \%$ hepatectomy + IL-6 treatment. ${ }^{\mathrm{B}} P<0.05 \mathrm{vs}$. WT mice undergoing $70 \%$ hepatectomy + vehicle treatment.

leagues have shown that there are IL-6-dependent and IL-6-independent phases of hepatocyte proliferation: the $\mathrm{G} 1$ replication phase is IL- 6 dependent, while the G1/S phase transition is independent of IL-6 (32). While many studies document that IL-6 is important for hepatic regeneration, other studies present conflicting data on IL-6's role in the hepatic regenerative response. During fulminant hepatic failure, early and sustained increases in IL- 6 blood levels are associated with inhibition of liver regeneration due to protein inhibitor of activated stat 3 upregulation (33). Similarly, IL-6 hyperstimulation in a mouse partial hepatectomy model causes a strong activation of stat 3 inhibitors and a delay and inhibition of cell cycle progression (34). This is also suggested by our data (presented in Table 4 and Figure 7), which show some decrease in liver weight/total body weight ratios and BrdU staining in WT animals treated with exogenous IL- 6 after partial hepatectomy. Thus, after massive hepatocyte loss, an early and rapid increase in IL- 6 may weaken the hepatic regenerative response via upregulation of stat 3 inhibitors $(33,34)$. Our current study also provides interesting data regarding the complexity of IL-6-mediated hepatocyte proliferation. Exogenous SCF administration to $I L-6^{-/-}$mice in the setting of partial hepatectomy appears to restore hepatocyte proliferation to near-normal and to upregulate p-stat 3 in the process, suggesting that SCF is integrally involved in IL-6-mediated hepatocyte proliferation and functions downstream of IL-6. An interesting aspect to this data, however, is the fact that the administration of exogenous SCF to WT mice did not result in a significant increase in hepatocyte proliferation, but did result in an increase in p-stat 3 levels. This suggests that additional regulatory mechanisms controlling hepatocyte proliferation must be operating in WT animals, preventing excessive hepatocyte proliferation from occurring.

The SCF receptor is c-kit (35), which is also considered to be a proto-oncogene. This further suggests that SCF may be involved in growth regulation. SCF and c-kit are expressed on many tumor cells, including neuroblastomas, small cell lung adenocarcinomas, and hepatomas (36-39). The latter indicates that liver-derived lineages can express and produce significant levels of SCF and c-kit, possibly associated with unrestricted growth. SCF in the liver is localized to hepatocytes surrounding the ductal epithelial cells, a probable focal point of hepatic regeneration $(23,24,40)$. A new drug, imatinib (Gleevec; Novartis Pharmaceuticals Corp., East Hanover, New Jersey, USA), is a protein kinase and c-kit inhibitor and is highly effective in treating stromal cell and other c-kit-positive tumors. Interestingly, this drug can be hepatotoxic, and the only mortality that has occurred in the early trials involved a patient who was taking acetaminophen regularly for fever and died of fulminant hepatic failure (31). This suggests that SCF may have

a

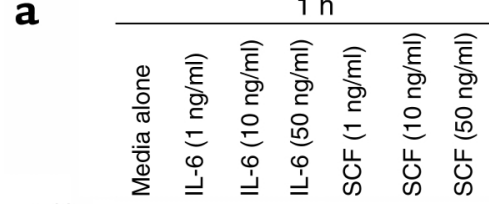

$40 \mathrm{~kb}-$

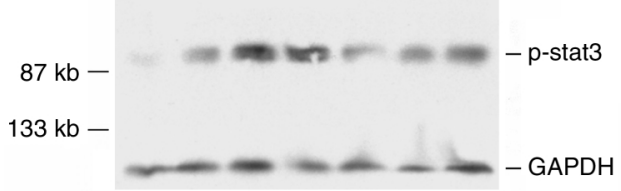

C

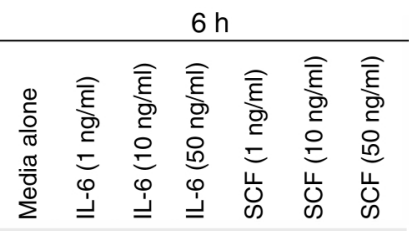

$40 \mathrm{~kb}-$

$87 \mathrm{~kb}-$

$133 \mathrm{~kb}-$

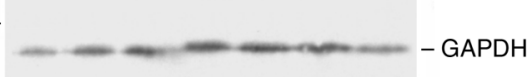

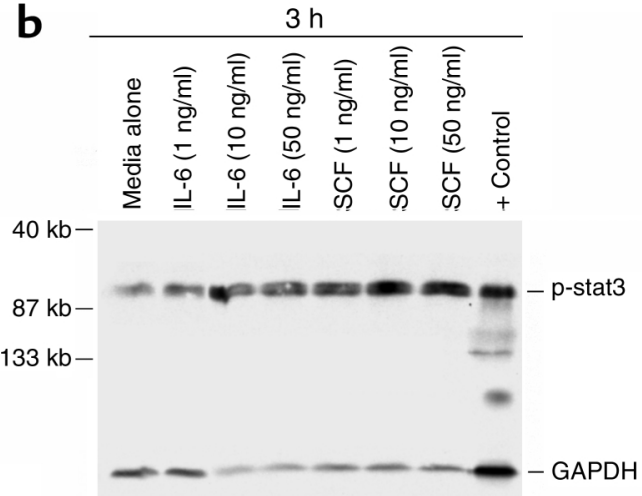

\section{Figure 9}

Representative Western blot analysis for cytosolic p-stat 3 levels in primary mouse hepatocytes stimulated with IL- 6 or SCF. These Western blots are representative blots from in vitro experiments in which primary mouse hepatocytes were stimulated with 1,10 , or $50 \mathrm{ng} / \mathrm{ml}$ of IL-6 or SCF. These experiments demonstrated that there is a significant increase in cytosolic p-stat 3 levels in response to both IL-6 and SCF at 1 hour (a), 3 hours (b), and 6 hours (c) of incubation. Note: Blots were stripped and reprobed for GAPDH in these Westerns. The GAPDH gels are separate from the $p$-stat 3 gels. The position of the molecular weight marker is not applicable to the GAPDH gel. 
a

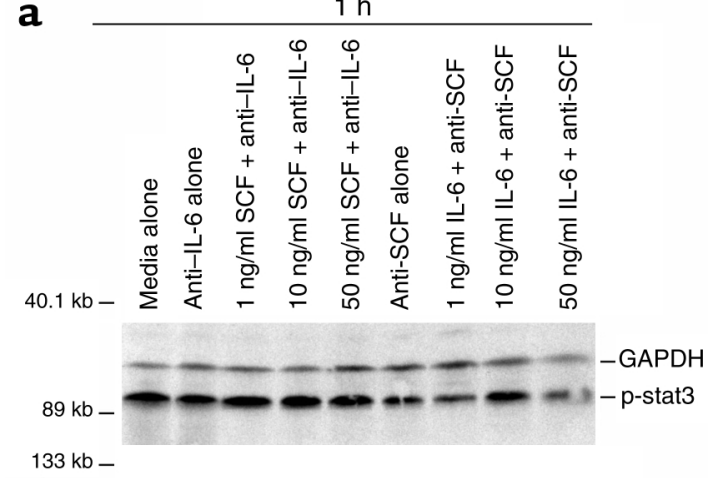

b
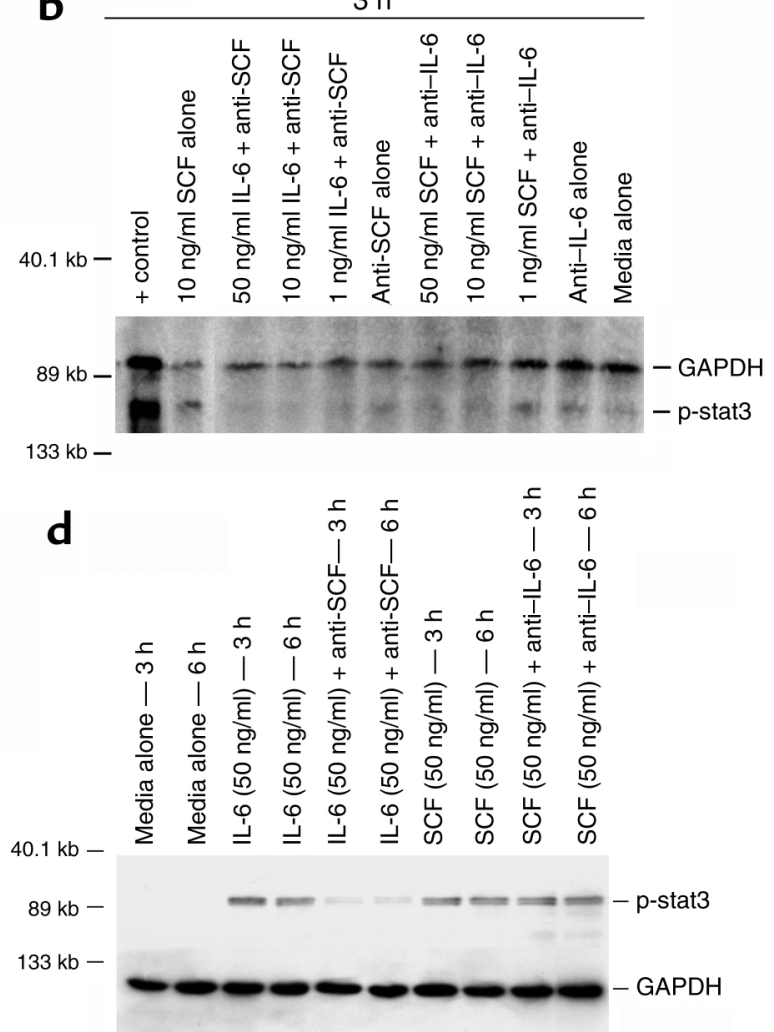

C

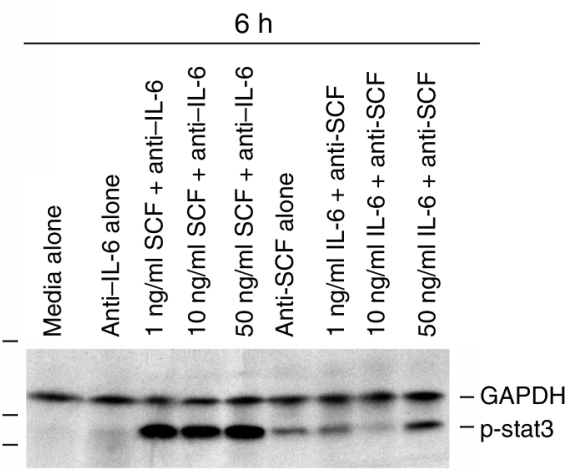

\section{Figure 10}

Representative Western blot analysis for cytosolic p-stat3 levels in primary mouse hepatocytes stimulated with IL-6 and incubated concurrently with anti-SCF or stimulated with SCF and incubated concurrently with anti-IL-6. These Western blots are representative blots from in vitro experiments in which primary mouse hepatocytes are stimulated with 1, 10, or $50 \mathrm{ng} / \mathrm{ml}$ of IL-6 and anti-SCF or 1,10 , or $50 \mathrm{ng} / \mathrm{ml}$ of SCF and anti-IL-6. These experiments demonstrated that p-stat 3 levels are decreased in cells stimulated with IL-6 and anti-SCF, particularly at the 3-hour and 6-hour timepoints. In contrast, minimal decreases in p-stat3 levels are seen in cells incubated with SCF and anti-IL-6. A double labeling technique was used for these gels; GAPDH is in the appropriate position for its molecular weight. (a-c) Timepoints 1, 3, and 6 hours. (d) The 3-hour and 6-hour timepoints demonstrating p-stat3 levels in cells stimulated with media alone or IL-6 or SCF alone at the $50 \mathrm{ng} / \mathrm{ml}$ dose, or IL-6 $(50 \mathrm{ng} / \mathrm{ml})+$ anti-SCF and SCF $(50 \mathrm{ng} / \mathrm{ml})+$ anti-IL-6.

important actions in maintaining hepatic homeostasis. Accelerated hepatic stat 3 expression is also seen in response to SCF during septic peritonitis (28), again suggesting that this molecule is important in maintaining the liver's health in a variety of disease states.

SCF and c-kit are present in normal as well as injured liver (41). SCF levels increase during hepatic fibrosis, in bile duct-ligated mice, and in the setting of human biliary obstruction (42-45). During fulminant hepatic failure, c-kit mRNA levels increase (46). Other studies also support our current investigations, suggesting a role for SCF during liver regeneration (47). Additional experimental data have also confirmed a relationship between IL- 6 and SCF in the hematopoietic system; more specifically, IL- 6 and its soluble receptor upregulate SCF, leading to hematopoietic progenitor cell expansion during extramedullary hepatopoiesis (48). IL-6 also modulates SCF-dependent human mast cell development (49). The data presented in this investigation also suggest that IL-6 upregulates hepatic SCF and that hepatic SCF is at least partially responsible for hepatocyte proliferation following partial hepatectomy. In addition, these responses appear to be mediated via a stat 3 signal transduction pathway. These data, in conjunction with the data presented in this manuscript, suggest that SCF is a part of IL-6-induced hepatocyte proliferation and that this pathway is likely important in the liver's regenerative recovery from partial hepatectomy.

Our current investigations indicate that there are high constitutive SCF levels within the liver. SCF is normally found as a transmembrane protein under homeostatic conditions and is solubilized after inflammatory stimuli induce the proper enzyme release to cleave it from the cell surface. This mechanism may allow a substantial SCF reservoir to be stored on the cell surface, ready for release upon liver injury. We hypothesize that solubilized SCF released during an acute injury could interact via c-kit receptors with the surrounding hepatocyte populations, functioning as a proliferative agent within the damaged tissue. Although hepatic homeostasis and regeneration likely involves multiple complex mechanisms and pathways, our current data suggest that SCF plays a significant role in maintaining and reestablishing the health of the liver. 


\section{Acknowledgments}

\section{This work was supported by NIH grants R01 DK-} 58106 and R01 DK-53224.

1. Hadjis, N.S., and Blumgart, L.H. 1990. Liver hyperplasia, hypertrophy and atrophy: clinical relevance. In Surgery of the liver and biliary tract. L.H. Blumgart, editor. Churchill Livingstone. New York, New York, USA. 61-71.

2. de la Mata, M., et al. 1990. Tumour necrosis factor production in fulminant hepatic failure: relation to aetiology and superimposed microbial infection. Clin. Exp. Immunol. 83:479-484.

3. Fausto, N., Laird, A.D., and Webber, E.M. 1995. Liver regeneration. 2 Role of growth factors and cytokines in hepatic regeneration. FASEB J. 9:1527-1536.

4. Colletti, L.M., Green, M., Burdick, M., Kunkel, S.L., and Strieter, R.M. 1998. Proliferative effects of CXC chemokines in rat hepatocytes in vitro and in vivo. Shock. 10:248-257.

5. Castilla, A., Prieto, J., and Fausto, N. 1991. Transforming growth factors beta 1 and alpha in chronic liver disease. Effects of interferon alfa therapy. N. Engl. J. Med. 24:933-940.

6. Jiang, W.G., and Hiscox, S. 1997. Hepatocyte growth factor/scatter factor, a cytokine playing multiple and converse roles. Histol. Histopathol. 12:537-555

7. Cressman, D.E., et al. 1996. Liver failure and defective hepatocyte regeneration in interleukin-6-deficient mice. Science. 274:1379-1383.

8. Hogaboam, C.M., et al. 1999. Novel CXCR2-dependent liver regenerative qualities of ELR-containing CXC chemokines. FASEB J. 13:1565-1574.

9. Yamada, Y., Webber, E.M., Kirillova, I., Peschon, J.J., and Fausto, N. 1999. Analysis of liver regeneration in mice lacking type 1 or type 2 tumor necrosis factor receptor: requirement for type 1 but not type 2. Hepatology. 28:906-913

10. Webber, E.M., Bruis, J., Pierce, R.H., and Fausto, N. 1998. Tumor necrosis factor primes hepatocytes for DNA replication in the rat. Hepatology. 28:1226-1234.

11. Selzner, M., Camargo, C.A., and Clavien, P.A. 1999. Ischemia impairs liver regeneration after major tissue loss in rodents: protective effects of interleukin-6. Hepatology. 30:469-475.

12. Rai, R.M., et al. 1996. Kupffer cell depletion by gadolinium chloride enhances liver regeneration after partial hepatectomy. Am. J. Physiol. 270:G909-G918.

13. Diehl, A.M., et al. 1995. Tumor necrosis factor-alpha modulates CCAAT/enhancer binding proteins-DNA binding activities and promotes hepatocyte-specific gene expression during liver regeneration. Hepatology. 22:252-261.

14. Zsebo, K.M., et al. 1990. Stem cell factor is encoded at the Sl locus of the mouse and is the ligand for the c-kit tyrosine kinase receptor. Cell. 63:213-224.

15. Shimizu, Y., Ashman, L.K., Du, Z., and Schwartz, L.B. 1996. Internalization of Kit together with stem cell factor on human fetal liver-derived mast cells: new protein and RNA synthesis are required for reappearance of Kit. J. Immunol. 156:3443-3449.

16. Matsui, Y., Zsebo, K.M., and Hogan, B.L. 1990. Embryonic expression of a haematopoietic growth factor encoded by the Sl locus and the ligand for c-kit. Nature. 347:667-669.

17. Kurata, H., Mancini, G.C., Alespeiti, G., Migliacco, A.R, and Migliacco, G. 1998. Stem cell factor induces proliferation and differentiation of fetal progenitor cells in the mouse. Br. J. Haematol. 101:676-687.

18. Grichnik, J.M., Burch, J.A., Burchette, J., and Shea, C.R. 1998. The $\mathrm{SCF} / \mathrm{KIT}$ pathway plays a critical role in the control of normal human melanocyte homeostasis. J. Invest. Dermatol. 111:233-238.

19. Costa, J.J., et al. 1996. Recombinant human stem cell factor (kit ligand) promotes human mast cell and melanocyte hyperplasia and functional activation in vivo. J. Exp. Med. 183:2681-2686.

20. Kunisada, T., et al. 1998. Murine cutaneous mastocytosis and epidermal melanocytosis induced by keratinocyte expression of transgenic stem cel factor. J. Exp. Med. 187:1565-1573.

21. Morimoto, M., Tsujimura, T., Kanakura, Y., Kitamura, Y., and Matsuda, H. 1998. Expression of c-kit and stem cell factor mRNA in liver specimens from healthy adult dogs. Am. J. Vet. Res. 59:363-366.

22. Omori, M., et al. 1997. Expression of alpha-fetoprotein and stem cell factor/c-kit system in bile duct ligated young rats. Hepatology. 25:1115-1122.

23. Rao, M.S., Yukawa, M., Omori, M., Thorgeirsson, S.S., and Reddy, J.K. 1996. Expression of transcription factors and stem cell factor precedes hepatocyte differentiation in rat pancreas. Gene Expr. 6:15-22.

24. Fujio, K., Evarts, R.P., Hu, Z., Marsden, E.R., and Thorgeirsson, S.S. 1994 Expression of stem cell factor and its receptor, c-kit, during liver regeneration from putative stem cells in adult rat. Lab. Invest. 70:511-516.
25. Higgins, G.M., and Anderson, R.M. 1931. Restoration of the liver of the white rat following partial surgical removal. Arch. Pathol. 12:186-202.

26. Lukacs, N.W., et al. 1996. Stem cell factor (c-kit ligand) influences neutrophil recruitment and histamine levels in allergic airway inflammation. J. Immunol. 156:3945-3951.

27. Glantz, S.A. 1987. Alternatives to analysis of variance and the t test based on ranks. In Primer of biostatistics. S.A. Glantz, editor. McGraw-Hill. New York, New York, USA. 287-331.

28. Bone-Larson, C.L., et al. 2000. Novel protective effects of stem cell factor in a murine model of acute septic peritonitis. Am. J. Pathol. 157:1177-1186

29. Colletti, L.M., Kunkel, S.L., Green, M., Burdick, M., and Strieter, R.M. 1996. Hepatic inflammation following $70 \%$ hepatectomy may be related to upregulation of epithelial neutrophil-activating protein-78. Shock. 6:397-402

30. Miyazawa, K., et al. 1995. Membrane bound Steel factor induces more persistent tyrosine kinase activation and longer life span of c-kit geneencoded protein than its soluble form. Blood. 85:641-649.

31. Berman, J., and O'Leary, T.J. 2001. Gastrointestinal stromal tumor workshop. Hum. Pathol. 32:578-582.

32. Selzner, M., and Clavien, P.A. 2000. Failure of regeneration of the steatotic rat liver: disruption at two different levels in the regeneration pathway. Hepatology. 31:35-42.

33. Kamohara, Y., et al. 2000. Inhibition of signal transducer and activator transcription factor 3 in rats with acute hepatic failure. Biochem. Biophys. Res. Commun. 273:129-135.

34. Wustefeld, T., Rakemann, T., Kubicka, S., Manns, M.P., and Trautwein, C. 2000. Hyperstimulation with interleukin 6 inhibits cell cycle progression after hepatectomy in mice. Hepatology. 32:514-522.

35. Zhang, S., Howarth, P.H., and Roche, W.R. 1996. Cytokine production by cell cultures from bronchial subepithelial myofibroblasts. Mast cells and airway inflammation in asthma c-kit ligand: a unique potentiator of mediator release by human lung mast cells. J. Pathol. 180:95-101.

36. Hibi, K., et al. 1991. Coexpression of the stem cell factor and the c-kit genes in small-cell lung cancer. Oncogene. 6:2291-2296.

37. Papadimitriou, C.A., et al. 1995. Recombinant human stem cell factor does exert minor stimulation of growth in small cell lung cancer and melanoma cell lines. Eur. J. Cancer. 31A:2371-2378.

38. Krystal, G.W., Hines, S.J., and Organ, C.P. 1996. Autocrine growth of small cell lung cancer mediated by coexpression of c-kit and stem cell factor. Cancer Res. 56:370-376.

39. Takahashi, H., Saitoh, K., Kishi, H., and Parson, P.G. 1995. Immunohistochemical localisation of stem cell factor (SCF) with comparison of its receptor c-Kit proto-oncogene product (c-KIT) in melanocytic tumours. Virchows Arch. 427:283-288.

40. Omori, M., Omori, N., Evarts, R.P., Teramoto, T., and Thorgeirsson, S.S. 1997. Coexpression of flt-3 ligand/flt-3 and SCF/c-kit signal transduction system in bile-duct-ligated SI and W mice. Am. J. Pathol. 150:1179-1187.

41. Fujio, K., et al. 1996. Coexpression of stem cell factor and c-kit in embryonic and adult liver. Exp. Cell Res. 224:243-250.

42. Gaca, M.D., Pickering, J.A., Arthur, M.J., and Benyon, R.C. 1999. Human and rat hepatic stellate cells produce stem cell factor: a possible mechanism for mast cell recruitment in liver fibrosis. J. Hepatol. 30:850-858.

43. Omori, M., Omori, N., Evarts, R.P., Teramoto, T., and Thorgeirsson, S.S. 1997. Coexpression of flt-3 ligand/flt-3 and SCF/c-kit signal transduction system in bile duct ligated SI and W mice. Am. J. Pathol 150:1179-1187.

44. Omori, M., et al. 1997 Expression of alpha-fetoprotein and stem cell factor/c-kit system in bile duct ligated young rats. Hepatology. 25:1115-1122

45. Tsuneyama, K., et al. 1999. Aberrant expression of stem cell factor on biliary epithelial cells and peribiliary infiltration of c-kit-expressing mast cells in hepatolithiasis and primary sclerosing cholangitis: a possible contribution to bile duct fibrosis. J. Pathol. 89:609-614.

46. Baumann, U., Crosby, H.A., Ramani, P., Kelly, D.A., and Strain, A.J. 1999. Expression of the stem cell factor receptor c-kit in normal and diseased pediatric liver: identification of a human hepatic progenitor cell? Hepatology. 30:112-117.

47. Fujio, K., Evarts, R.P., Hu, Z., Marsden, E.R., and Thorgeirsson, S.S. 1994. Expression of stem cell factor and its receptor, c-kit, during liver regeneration from putative stem cells in adult rat. Lab. Invest. 70:511-516.

48. Peters, M., Solem, F., Goldschmidt, J., Schirmacher, P., and Rose-John, S 2001. Interleukin- 6 and the soluble interleukin- 6 receptor induce stem cell factor and Flt-3L expression in vivo and in vitro. Exp. Hematol. 29:146-155.

49. Kinoshita, T., Sawai, N., Hidaka, E., Yamashita, T., and Koike, K. 1999. Interleukin-6 directly modulates stem cell factor-dependent development of human mast cells derived from CD34(+) cord blood cells. Blood. 94:496-508. 